\title{
Mobilya üretimde kullanılan farklı malzemelerin web madenciliği yöntemleri ile değerlendirilmesi
}

\author{
Eser Sözen ${ }^{1}$ (D), Timuçin Bardak ${ }^{* 2}$ (D)
}

$\ddot{\mathbf{O} z}$

İnternet günümüzde yaygın olarak kullanılan ve içerisinde birçok alandan faydalı bilgiler bulunduran zengin bir kaynaktır. Web madenciliği ise temelde tüketiciler ve tüketicilerin pazar eğilimleri hakkındaki bilgileri bulmaya yardımcı olan bir alandır. Doğru ve güvenilir bilgi, her endüstri için kritik bir konu haline dönüşmüştür. Firmalar web madenciliği teknikleri ile elde edilen anlamlı bilgiler sayesinde daha doğru kararlar alabilmektedir. Bu çalışmada, E-ticaret web sayfalarında farklı mobilya ürünleri hakkında yapılan yorumlar, Rapidminer yazılımı ile elde edilmiştir. Ahşap ve metal malzemeden üretilmiş mobilyalar hakkında elde edilen veriler, web madenciliği ile değerlendirilmiştir. Bu amaçla günlük hayatta yaygın olarak kullanılan çalışma masası, kütüphane ve sandalye mobilyaları seçilmiştir. Tüm mobilya türleri için ayrı ayrı web ve metin madenciliği ile kelime bulutları oluşturulmuştur. Bu sayede mobilya ürünü üzerine yapılan yorumlardaki anahtar kelimeler görselleştirilmiştir. Çalışma sonuçlarına göre ahşap sandalyelerde "sağlamlık" metal sandalyelerde "oturma" ile ilgili yorumlar öne çıkmıştır. Ahşap ve metal çalışma masalarında "güzel" kelimesi öne çıkarken, ahşap kütüphanelerde "kolay", metal kütüphanelerde "ofis" ve "paketleme" anahtar kelimeleri ortaya çıkmıştır.

Anahtar kelimeler: Web madenciliği, Mobilya, Müşteri memnuniyeti, E-ticaret

\section{Evaluation of different materials used in furniture production with web mining methods}

\begin{abstract}
The internet is a rich resource that is widely used today and contains useful information from many fields. On the other hand, web mining, is basically a field that helps to find information about consumers and consumers' market trends. Accurate and reliable information has become a critical issue for every industry. Companies can make more accurate decisions thanks to the meaningful information obtained by web mining techniques. In this study, comments about different furniture products on e-commerce web pages were obtained with Rapidminer software. The data obtained about furniture made of wood and metal materials were evaluated by web mining. For this purpose, desk, library and chair furniture, which are widely used in daily life, were chosen. Word clouds were created by web and text mining separately for all furniture types. In this way, the keywords in the comments on the furniture product were visualized. According to the results of the study, the comments about "durability" in wooden chairs and "sitting" in metal chairs came to the fore. While the word "beautiful" stood out in wooden and metal desks, the keywords "easy" in wooden libraries, "office" and "packaging" in metal libraries.
\end{abstract}

Keywords: Web mining, Furniture, Customer satisfaction, E-commerce 


\section{Giriş}

Dijital teknolojilerin hayatımızdaki yeri arttıkça, tüketicilerin tercih, tutum ve davranışlarında da değişiklikler ortaya çıkmıștır. Alışveriş yapma alışkanlıkları ve yöntemleri bu değişikliklerin başında gelmektedir (Ülger ve Toksarı 2020). Dijital teknolojiler, tüketicilere doğrudan mağazadan alışveriş yapmanın yanında, internet üzerinden seçim yapabilme alternatifleri de sunmaktadır (Laohapensang, 2009). Bu durum, dijital ortamda yapılan alış-veriş hacminde de artışlara neden olmuştur. E- ticaret firmaları üzerinden yapılan alışverişin artmasında, trafik sıkışıklığı, kalabalık müşteri yoğunluğu, iş hayatından dolayı sınırlı süre, park alanı gibi sorunlar da etkili olmaktadır (Suki ve ark., 2008).

Aralık 2019'da Koronavirüs (COVID-19) salgınının ortaya çıkmasıyla tüketicilerin alışveriş alışkanlıkları daha da değişmiştir. Salgın öncesi alışverişi market, mağaza ve AVM'lerden yapılan bazı ürünlerin, salgın sonrası e- ticaret sitelerinden yapıldığı görülmüştür. Alışverişin hızlı olması, ürüne ulaşımın kolay olması, sürekli kampanya, indirim ve puan sistemlerinin olması, temassız ödeme imkânı, seçeneklerin fazla olması ve evden çıkmadan alışverişin tamamlanması bu artışın sebepleri olarak gösterilebilir (URL-1). Eticaret sitelerine artan yönelim, talep yoğunluğunun karşılanmasında aksamalara neden olmuştur. Buna bağlı olarak E- ticaret sitelerine gelen müşteri şikâyet sayıları da artmıştır (Güven, 2020). Geleneksel ticarette olduğu gibi, E-ticaret ortamında da müşteri memnuniyeti firmaların başarısında önemli bir yer tutar (Patterson ve ark., 1997). Müşteri memnuniyetinin ve sürekliliğinin sağlanması ne kadar zor bir durum ise, kaybetmek de bir o kadar kolaydır. Satış sonrası hizmetlerin olumlu veya olumsuz olması bu durumun en önemli sebeplerindendir. Piyasa şartlarında tutunmak ve büyümek isteyen işletmeler, satışlara verdiği önemi satış sonrası da sürdürmelidir. Günümüzde yeni müşteriye ulaşmanın zorluğu düşünüldüğünde, mevcut müşterinin elde tutulması daha doğru bir strateji olarak karşımıza çıkmaktadır. Özellikle internet üzerinden yapılan alışverişlerde, mevcut müşterinin memnuniyeti ile yeni müşterilere ulaşma akımı (trendi) bu durumu desteklemektedir (Türedi, 2010; Akyüz ve ark., 2017). İnternet üzerinden yapılan alışverişlerin eve teslim edilmesi hususundaki prosedür, lojistik hizmeti veren firmalar ve müşteri tarafından benimsenmiştir. Ancak, müşterinin ürün tesliminde evde olmaması gibi nedenlerden dolayı tekrarlanan teslimatlar, ciddi zorluklar ve maliyetler oluşturmaktadır (Chen ve ark., 2019). Gelişen teknolojiler sayesinde kargo şirketleri ve nakliyeciler kapasite, güzergâh ve eşleştirme gibi fonksiyonlarla bu zorlukların yönetilmesinde bilgi ve beceri sahibi olmuşlardır (Sarkis ve ark., 2004).

Web sayfaları, firmaların müşterilerine ulaşma noktasında yeni bir yaklaşım olarak karşımıza çıkmaktadır. Reklam, tanıtım, algı oluşturma ve pozitif etki bırakma gibi işlemleri web sayfaları ile yapan firmalar, müşterileri ile etkileşimin sürdürülmesine önem vermişlerdir. $\mathrm{Bu}$ etkileşim, müşteriler hakkında daha fazla bilgi edinme, satın aldıkları ürün hakkındaki görüşlerini öğrenme ve müşteri memnuniyetini kullanarak diğer firmalarla rekabet edebilme özelliklerini arttırmaktadırlar (İnan ve Doğan 2006).

Verinin öneminin her geçen gün arttığı günümüzde, bu verilerin sinıflandırılması, nitelik ve nicelik olarak kategorize edilmesi ve bunlara bağlı olarak anlamlı sonuçların ortaya çıkarılması veri madenciliğinin de önemini arttırmıştır. Veri madenciliğinin alt alanlarından biri olan web madenciliği de, web sayfalarındaki verilerden ve belgelerden bilgilerin ayıklanması, analiz edilmesi ve anlamlı sonuçların elde edilmesini sağlamaktadır (Bardak ve Bardak 2019). Veri madenciliği teknikleri karmaşık problemlerin çözümünde oldukça etkili bir yöntemdir ve birçok farklı alanda verimliliği artırmak için kullanılmaktadır (Djenouri ve ark., 2018; Khanbabaei ve ark., 2018; Zhang ve ark., 2018; Beunza ve ark., 2019). 
Marka ve model olarak kendini ispat etmiş birçok ürün grubu internet üzerinden kolaylıkla satın alınabilmektedir. Ancak mobilya ve türevlerinin internet üzerinden alışverişinde müşteriler bazı tedirginlikler yaşamaktadır. MOSDER (2015), müşterilerin Eticaret yöntemi yerine klasik alışverişi tercih etme nedenlerini aşağıdaki gibi sıralamıştır (özetlenmiştir).

• Ürüne dokunarak inceleme imkânının olmaması ve daha önce internet üzerinden alışveriş deneyiminin olmaması,

- Ödeme ile ilgili kart/kişisel bilgilerinin internet ortamında paylaşılmak istenmemesi,

- Hasarlı veya yanlış ürün gelme riskinin üstlenilmemesi,

- Fiyat üzerinde pazarlık payının olmaması.

Yukarıdaki etkenler internet üzerinden mobilya alımında etkili olmaktadır. Diğer taraftan masa, sandalye ve kütüphane gibi küçük mobilyaların web üzerinden alışverişi oldukça fazladır. Birçok bilimsel çalışmada (Yurtay ve ark., 2016; Bardak ve ark., 2018a,b; Karayılmazlar ve ark., 2019) mobilyalar hakkında çeşitli yollarla elde edilen verilerden anlamlı bilgiler çıkartılmıştır. Fakat web madenciliği tekniklerini kullanarak mobilyada kullanılan malzemelerin kullanıcı yorumlarının analiz edildiği bir çalışmaya rastlanmamıştır.

$\mathrm{Bu}$ çalışmada, internet üzerinden metal veya ahşap masa, sandalye ve kütüphane alışverişi yapmış kullanıcıların aldığı ürünler hakkındaki yorumları malzeme açısından web madenciliği ile değerlendirilmiştir. Aynı zamanda kelime bulutları oluşturulmuş ve mobilya üretiminde kullanılan farklı malzemeler için anahtar kelimeler görselleştirilmiştir. Makalede, e-ticaret sitelerinin verilerine dayalı olarak mobilyada kullanılan farklı malzemeler için kullanıcı deneyimlerinden anlamlı bilgilerin çıkarılması hedeflenmiştir.

\section{Materyal ve Metot}

\subsection{Materyal}

Bu çalışmada, mobilya üretimde kullanılan farklı malzemelerin kullanım deneyimleri, web madenciliği teknikleri ile incelenmiştir. Bu amaçla, ahşap ve metal malzemeler seçilmiş ve bu malzemeler ile üretilen çalışma masası, kütüphane ve sandalye hakkında yapılan yorumlar toplanmıştır. E-ticaret siteleri yorumların elde edildiği veri kaynağı olarak belirlenmiştir. Daha sonra metin madenciliği ile her bir mobilya ve malzeme türü için anahtar kelimeler belirlenmiştir. Şekil 1'de mobilya üretimde kullanılan malzemeler hakkında yapılan yorumların analizi için kullanılan adımlar gösterilmiştir.

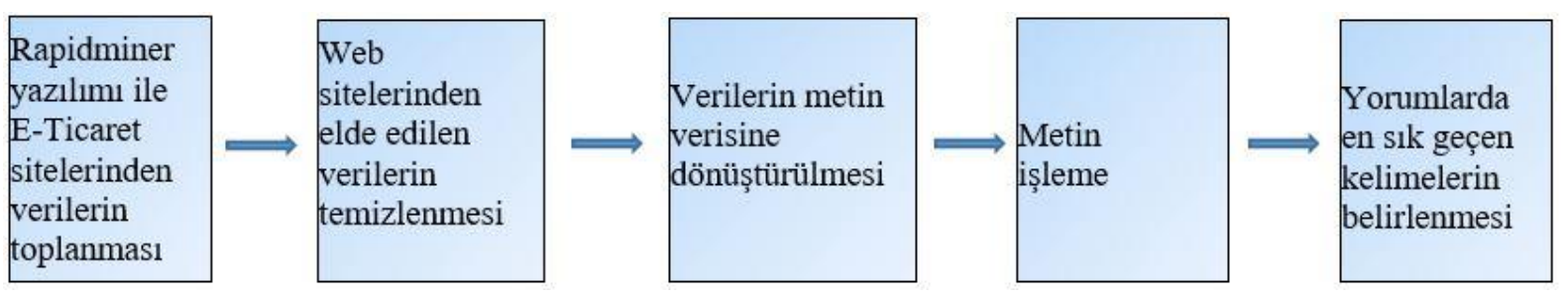

Şekil 1. Mobilya üretimde kullanılan malzemeler hakkında yapılan yorumların analizi için kullanılan adımlar 


\subsection{Metot}

Çalışma yönteminde, Rapidminer yazılımı web ve metin madenciliği tekniklerinden faydalanmak için kullanılmıştır. Rapidminer bilimsel çalışmalarda yaygın olarak kullanılan bir veri madenciliği platformudur (Avcı ve Bardak 2018; Sözen ve ark., 2018; Yagci ve Das 2018; Beunza ve ark., 2019; Oliveira ve ark., 2019). Platformda veri madenciliği için ihtiyaç duyulan çeşitli araçlar bulunmaktadır. Aynı zamanda kullanıcı dostu bir ara yüze sahiptir. Rapidminer yazılımında yer alan operatörler kullanılarak ilgili süreçler oluşturulmaktadır. Her bir operatörün kendine özgü bir görevi vardır. Operatörler, veri okumak, model oluşturmak, performans ölçmek gibi görevleri yerine getirebilirler. Operatörler uç ucu eklenerek prosesler oluşturulur ve bu sayede veri madenciliği ile hedeflenen problemler çözülür. Şekil 2'de Rapidminer yazılımının operatörlerden oluşan kullanıcı ara yüzü gösterilmiştir.

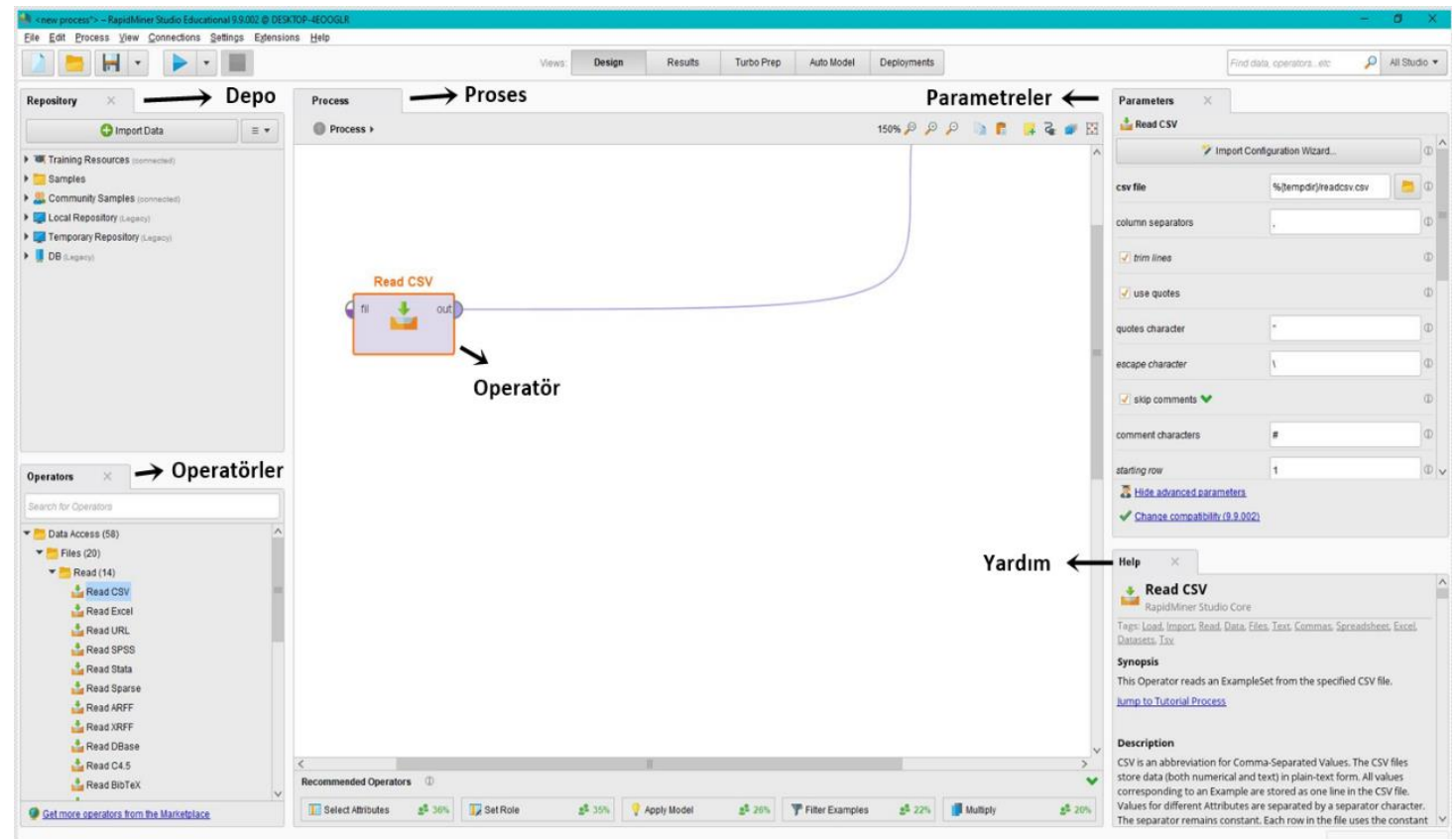

Şekil 2. Rapidminer yazılımının operatörlerden oluşan kullanıcı ara yüzü

Çalışmada ilk olarak e-ticaret web sitelerinden her bir malzeme ve mobilya türü için ayrı ayrı yorumlar toplanmıştır. Şekil 3'te e-ticaret sitelerinden yorumları elde etmek için oluşturulan operatörlerin prosesi gösterilmiştir.

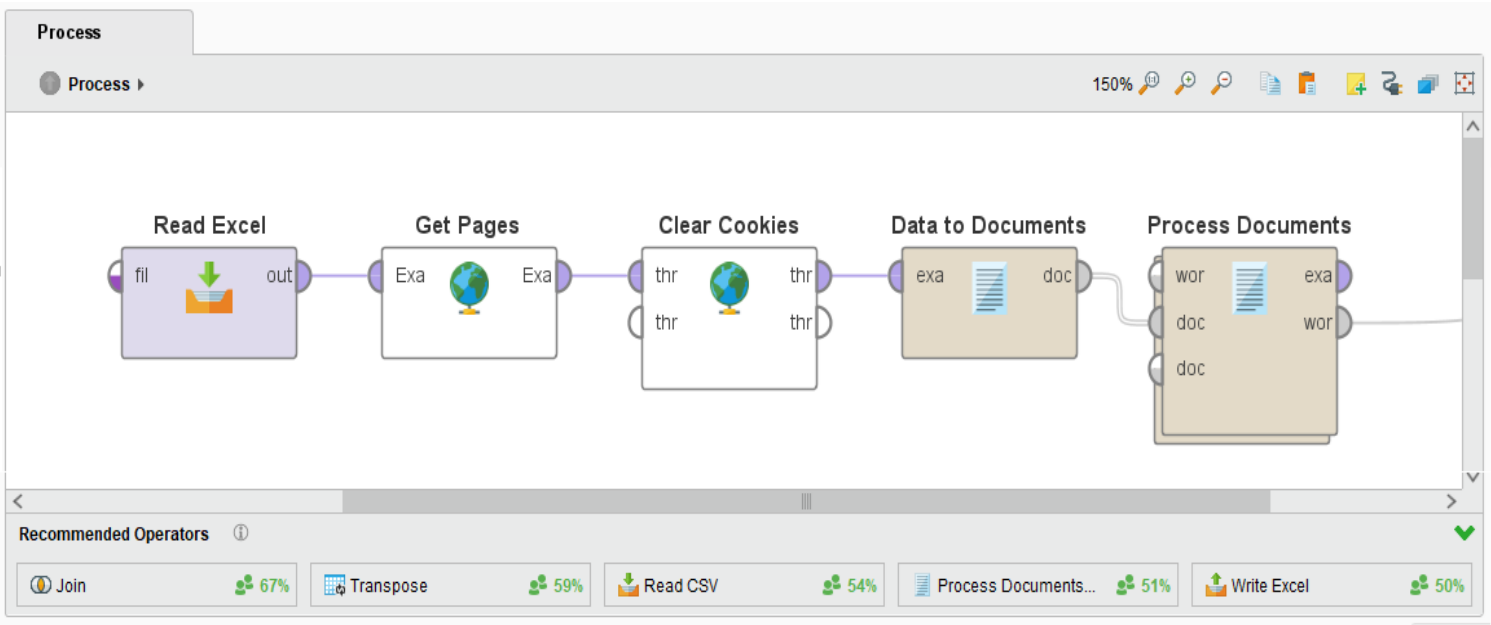

Şekil 3. E-ticaret sitelerinden yorumları elde etmek için operatörlerden oluşmuş proses 
Veriler toplandiktan sonra metin madenciliği işlemi gerçekleştirilmiştir. Metin madenciliği, genellikle yapılandırılmamış metin belgelerinin kalıplarını veya önemli bilgilerin çıkartılma sürecini ifade eder (Ribeiro ve ark., 2019). Toplamda 2871 adet yorumdan sağlanan metin verisi ön işleme ile analize hazırlanmış ve en sık kullanılan kelimeler belirlenmiştir. Metin madenciliği ile yorumlarda en sik geçen kelimeleri belirlemek için kullanılan proses Şekil 4'te gösterilmiştir.

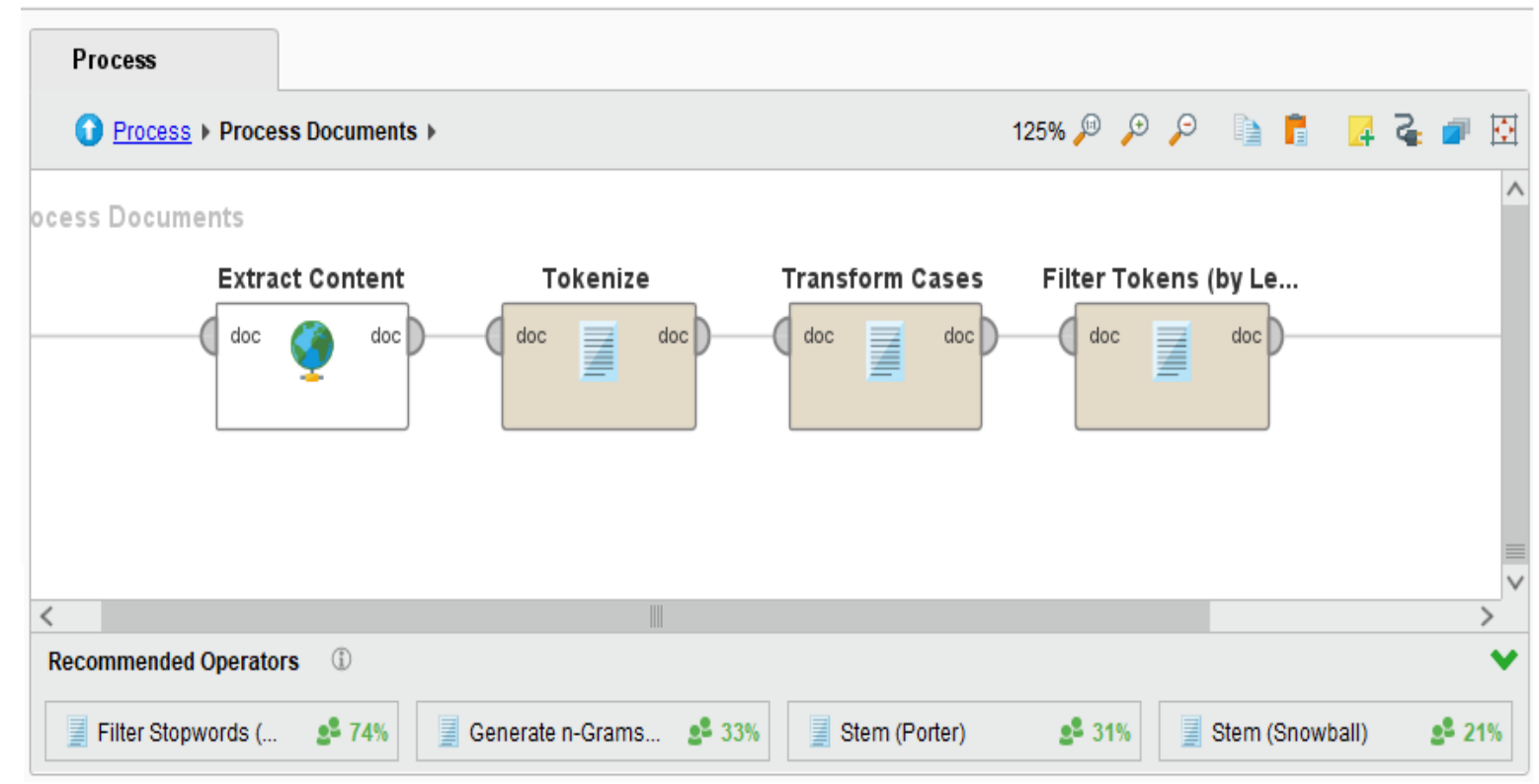

Şekil 4. Metin madenciliği ile yorumlarda en sık geçen kelimeleri belirlemek için kullanılan proses

Web ve metin madenciliği ile ahşap ve metal malzemeden üretilmiş çalışma masası, kütüphane ve sandalye hakkında yapılan yorumlarda en sık geçen kelimeler ayrı ayrı belirlenmiş ve anahtar kelimeler görselleştirilmiştir. Şekil 5'te Rapidminer yazılımı ile kelime bulutlarının oluşturulması gösterilmiştir.

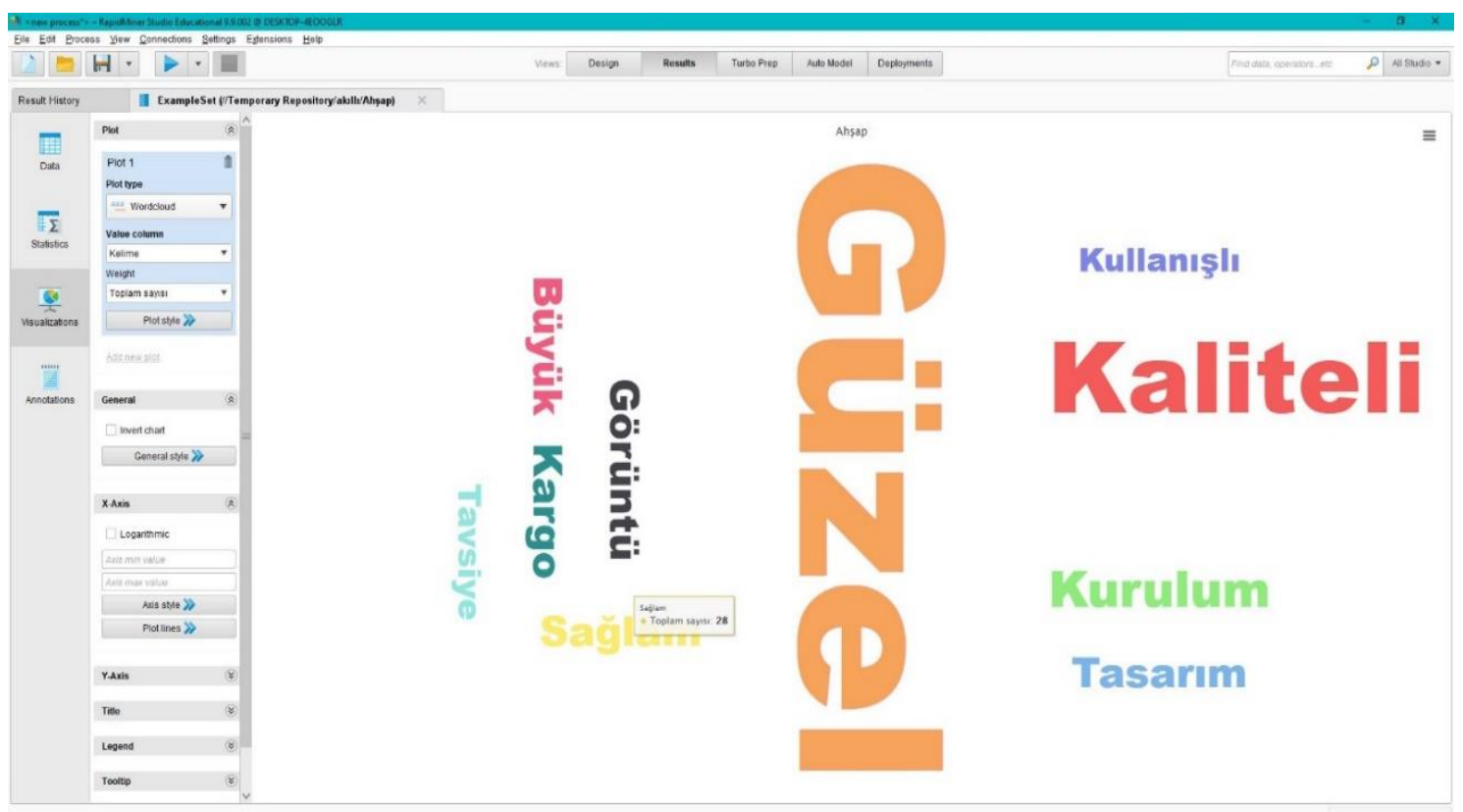

Şekil 5. Rapidminer yazılımı ile kelime bulutlarının oluşturulması 


\section{Bulgular ve Tartışma}

E-ticaret internet sayfalarının web ve metin madenciliği ile analiz edilmesi sonucu ahşap ve metal malzemeden üretilmiş sandalye hakkında yapılan yorumlarda en sık geçen ilk 10 kelime değerlendirilmiştir. Elde edilen verilerden kelime bulutları ile anahtar kelimeler görselleştirilmiştir.

Kelime bulutları, metinde en sık geçen kelimeleri görsel olarak vurgulayarak anahtar kelimeleri göstermektedir. Bu sayede okuyucular bir bakışta metnin ana temasını ve önem derecesini anlayabilirler. Kelime bulutlarındaki anahtar kelimelerin büyüklügüu, ilgili kelimenin önemi ile doğru orantılı olarak değişmektedir. (Wen-Xiang ve ark., 2019). Ahşap ve metal malzemeden üretilmiş sandalye hakkında yapılan yorumlarda en sık geçen kelimeler Çizelge 1'de, oluşturulan kelime bulutu Şekil 6'da gösterilmiştir.

Çizelge 1. Ahşap ve metal malzemeden üretilmiş sandalye hakkında yapılan yorumlarda en sık geçen kelimeler

\begin{tabular}{|c|c|c|c|}
\hline \multicolumn{4}{|c|}{ SANDALYE } \\
\hline \multicolumn{2}{|c|}{ Ahşap Malzeme } & \multicolumn{2}{c|}{ Metal Malzeme } \\
\hline Kelime & Toplam sayısı & Kelime & Toplam sayısı \\
\hline Sağlam & 39 & Oturma & 60 \\
\hline Paketleme & 26 & Memnun & 59 \\
\hline Harika & 23 & Performans & 54 \\
\hline Memnun & 22 & Görüntü & 53 \\
\hline Rahat & 22 & Detaylı & 42 \\
\hline Ürünü & 22 & Minder & 34 \\
\hline Mükemmel & 19 & Rahatsız & 34 \\
\hline Renk & 17 & Ayaklar & 29 \\
\hline Fiyat & 15 & Kalite & 28 \\
\hline Teslimat & 15 & Boya & 27 \\
\hline
\end{tabular}

Ahşap Sandalye

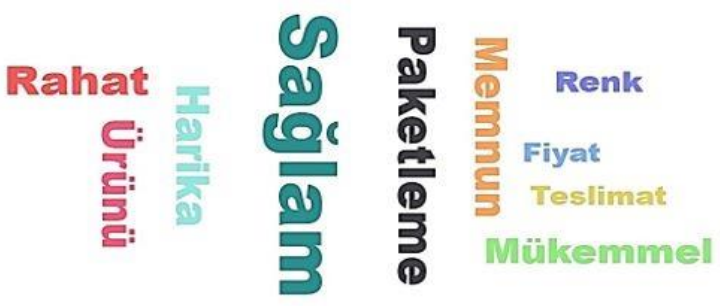

Metal Sandalye

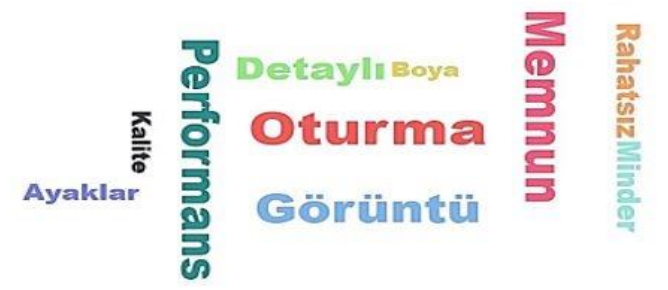

Şekil 6. Ahşap ve metal malzemeden üretilmiş sandalye hakkında yapılan yorumlarda en sık geçen kelimeler için oluşturulmuş kelime bulutu 
Ahşap malzemeden üretilmiş sandalye hakkında yapılan yorumlarda en sık geçen kelimeler "sağlam", "paketleme", "harika", "memnun", "rahat", "mükemmel", "renk", "fiyat" ve "teslimat" olarak belirlenmiştir. Metal malzeme için yapılan yorumlarda ise en sık geçen kelimeler "oturma", "memnun", "performans", "görüntï”, “detaylı", “minder", "rahatsı", "ayaklar", "kalite" ve "boya" olarak bulunmuştur. Ahşap ve metal sandalyelere yapılan yorumlardaki sık geçen kelimeler kıyaslandığında temel farklılık ahşap malzemede daha çok "harika", "memnun", "rahat", "mükemmel" gibi olumlu kelimeler ağırlıkta bulunurken, metal malzemede mobilyanın kullanımı ile ilgili "oturma", "performans", "minder" ve "kalite" gibi ağırlıkta görülmektedir. Bu durumda kullanıcıların ahşap sandalye için "estetik", metal sandalye için ise "fonksiyonellik" kelimelerini öne çıkardığı söylenebilir. Ahşap ve metal malzemeden üretilmiş çalışma masası hakkında yapılan yorumlarda en sık geçen ilk 10 kelime Çizelge 2'de, oluşturulan kelime bulutu Şekil 7'de gösterilmiştir.

Çizelge 2. Ahşap ve metal malzemeden üretilmiş çalışma masası hakkında yapılan yorumlarda en sık geçen kelimeler

\begin{tabular}{|c|c|c|c|}
\hline \multicolumn{4}{|c|}{ ÇALIŞMA MASASI } \\
\hline \multicolumn{2}{|c|}{ Ahşap Malzeme } & \multicolumn{2}{c|}{ Metal Malzeme } \\
\hline Kelime & Toplam sayısı & Kelime & Toplam sayısı \\
\hline Güzel & 128 & Güzel & 87 \\
\hline Kaliteli & 64 & Retro & 38 \\
\hline Kurulum & 31 & Sağlam & 38 \\
\hline Görüntü & 28 & Kullanışıl & 32 \\
\hline Kargo & 28 & Hizlı & 28 \\
\hline Sağlam & 28 & Fiyat & 26 \\
\hline Büyük & 26 & Kişisel & 22 \\
\hline Tasarım & 26 & Kolay & 22 \\
\hline Kullanışıı & 25 & Küçük & 17 \\
\hline Tavsiye & 25 & Basit & 15 \\
\hline
\end{tabular}

\section{Ahşap Çalışma Masası}

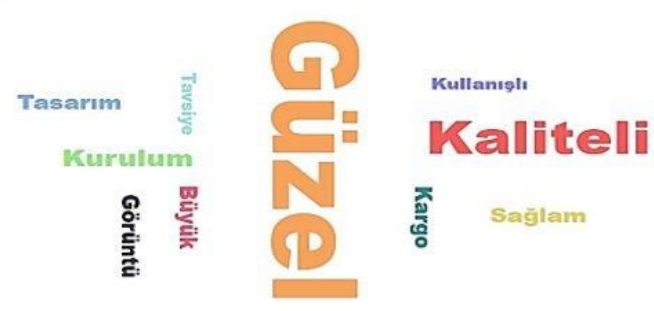

Metal Çalışma Masası

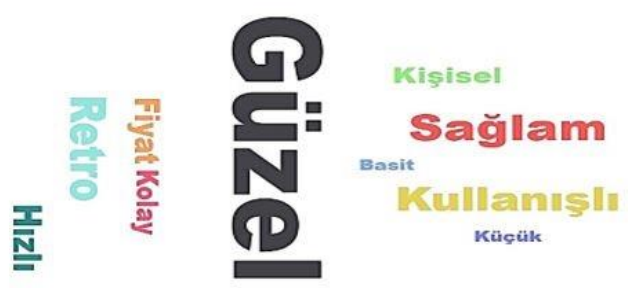

Şekil 7. Ahşap ve metal malzemeden üretilmiş çalışma masası hakkında yapılan yorumlarda en sık geçen kelimeler için oluşturulmuş kelime bulutu 
Ahşap malzemeden üretilmiş çalışma masası hakkında yapılan yorumlarda en sık geçen kelimeler "güzel”, "kaliteli”,"kurulum”, “görüntü”, "kargo", "sağlam”, "büyük", "tasarım”, "kullanışlı" ve "tavsiye" olarak belirlenmiştir. Metal malzeme için yapılan yorumlarda ise en sık geçen kelimeler "güzel”, "retro", "sağlam", "kullanışlı", "hızlı", "fiyat", "kişisel”, "kolay", "küçük" ve "basit" olarak bulunmuştur. Ahşap malzemeden üretilmiş çalışma masalarında "kaliteli", "tasarım", "görüntü" gibi kelimelerin öne çıkması, ahşap malzemenin estetik açıdan kullanıcıları etkilendiğini düşündürmektedir. Metal malzemeden üretilmiş çalışma masalarında ise "retro" kelimesinin çok sık geçmesi metalin yakın geçmiş modasını kullanıcılara hatırlattığını düşündürmektedir. Ayrıca çalışma masasının üretiminde metal ve ahşap malzemelere yer verilmesinin kullanıcıları memnun ettiği sonucu çıkartılabilir. Ahşap ve metal malzemeden üretilmiş kütüphane hakkında yapılan yorumlarda en sık geçen ilk 10 kelime Çizelge 3'te, oluşturulan kelime bulutu Şekil 8'de gösterilmiştir.

Çizelge 3. Ahşap ve metal malzemeden üretilmiş kütüphane hakkında yapılan yorumlarda en sık geçen ilk 10 kelime

\begin{tabular}{|c|c|c|c|}
\hline \multicolumn{4}{|c|}{ KÜTÜPHANE } \\
\hline Ahşap Malzeme & \multicolumn{2}{c|}{ Metal Malzeme } \\
\hline Kelime & Toplam sayısı & Kelime & Toplam sayısı \\
\hline Kolay & 64 & Ofis & 25 \\
\hline Monte & 42 & Paketleme & 25 \\
\hline Kurulum & 38 & Fiyat & 24 \\
\hline Fiyat & 36 & Vida & 22 \\
\hline Uygun & 36 & Ayaklar & 21 \\
\hline Kullanışlı & 34 & Uygun & 21 \\
\hline Duvar & 33 & Bilgisayar & 20 \\
\hline Küçük & 33 & Büyük & 20 \\
\hline Sağlam & 30 & Ufak & 20 \\
\hline Büyük & 25 & Hafif & \\
\hline
\end{tabular}

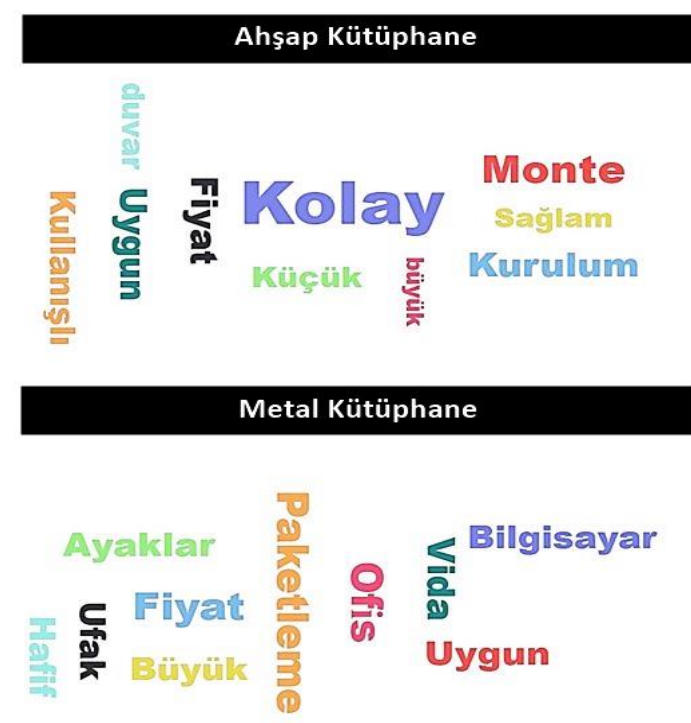

Şekil 8. Ahşap ve metal malzemeden üretilmiş kütüphane hakkında yapılan yorumlarda en sık geçen kelimeler için oluşturulmuş kelime bulutu 
Ahşap malzemeden üretilmiş kütüphane hakkında yapılan yorumlarda en sık geçen kelimeler "kolay", "monte", "kurulum", "fiyat", "uygun", "kullanışl1", "duvar", "küçük", "sağlam" ve "büyük" olarak belirlenmiştir. Metal malzeme için yapılan yorumlarda ise en sık geçen olarak "ofis", "paketleme", "fiyat", "vida”, “ayaklar", "uygun”, "bilgisayar", "büyük", "ufak" ve "hafif" bulunmuştur. Ahşap malzemede üretilmiş kütüphanede " kolay", "monte" ve" kurulum" gibi kelimeler ön planda olduğu için montajlamadan kullanıcıların memnun olduğu sonucu çıkartılabilir. Metal malzemeden üretilmiş kütüphanelerde ise "ofis" "paketleme" ve "fiyat" kelimeleri ön plandadır. Bu durum metal kütüphanelerin daha çok iş hayatında kullanıldığını düşündürmektedir. Birçok bilimsel çalışmada kelime bulutları kullanılarak sıklık analizleri gerçekleştirilmektedir (Zhou ve ark., 2018; Li ve ark., 2020; Schedlbauer ve ark., 2021). Bu yolla veriler görselleştirilebilir ve kapsamlı bir şekilde yorumlanabilir.

\section{Sonuçlar ve Öneriler}

Mobilya endüstrisi hem sağladığı istihdam hem de ekonomik anlamda oluşturduğu katma değer açısından her gelişmiş ülke için önemlidir. Bu endüstride birçok firma rekabette avantaj sağlamak için tüketicileri anlamak istemektedir. Aynı zamanda müşterilerini daha doğru ve daha hızlı analiz etmek için yeni yollar aramaktadır. Bu bağlamda web madenciliği, büyük gelişme potansiyeline sahip olan ve tüketicileri doğru anlamak için kullanılabilen yeni araştırma konularındandır. Bununla birlikte bilim dünyasında farklı alanlarda web madenciliğine olan ilgi hızla artmaktadır. Bu çalışmada sunulan bilgiler, üretim ve tasarım alanında karar vericilere fayda sağlayacaktır. Yapılan çalışma sonucunda aşağıda sunulan sonuçlar çıkarılmıştır.

- Rapidminer programında gerçekleştirilen analiz sonuçlarına göre; aynı mobilya türünde metal ve ahşap malzemeler kullanıldığında yapılan yorumların anahtar kelimelerinde önemli farklılıklar olduğu görülmüştür. Bu durum farklı ürünlerde aynı malzeme kullanımının her zaman uygun olamayacağını doğrulamaktadır.

- Çalışma kapsamında oluşturulan kelime bulutlarına göre; ahşap ve metal kütüphane mobilyalarına yapılan yorumlardaki anahtar kelimeler, daha çok kullanım ile ilgili olurken, ahşap ve metal çalışma masasında anahtar kelimeler daha çok estetik ile ilgilidir.

- Elde edilen veriler ile mobilyaların kullanım yerindeki tüketici bilgilerini çıkartmak için web madenciliğinden faydalanarak daha kaliteli, estetik ve kullanışlı mobilyaların üretiminde referanslar sağlanabilir.

\section{Yazar Katkıları}

Eser Sözen: Çalışma konusunun belirlenmesi, verilerin elde edilmesi, verilerin analiz edilmesi ve yorumlanması, makalenin yazılması. Timuçin Bardak: Deney tasarımının yapılması, verilerin analiz edilmesi, makalenin yazılması.

\section{Kaynaklar}

Akyüz, İ., Akyüz, K.C., Ersen, N., Beker, M. (2017), A Research on the Customer Relationship Management in the Furniture and Other Forest Products Business (Istanbul Provincial Sample), Kastamonu Univ., Journal of Forestry Faculty, 17(1), 88-98.

Avcı, Ö., Bardak, T. (2018), Halkla ilişkiler kapsamında bartın tarihi galla (kadınlar) pazarı satıcılarının mutluluğunun veri madenciliğine dayalı analizi, in: Uluslararası Marmara Fen ve Sosyal Bilimler Kongresi 2018 Bildiriler Kitabı, Kocaeli/Türkiye, pp: 137-144. 
Bardak, S., Bardak, T. (2019), Evaluation of demand for furniture products by web mining. 4th International Symposium on Innovative Approaches in Engineering and Natural Sciences, 22-24 November, Samsun, TURKEY

Bardak, T., Avcı, Ö., Kayahan, K., Bardak, S. (2018a), Data mining based analysis of traditional store and virtual store preference in the purchase of furniture, in: 6th International Conference on Science Culture and Sport, pp: 645-652.

Bardak, T., Peker, H., Bardak, S. (2018b), Effects examination of the factors affecting choice of type of furniture with data mining technique (decision tree), International Journal of Ecosystems and Ecology Science, 8(2), 249-252.

Beunza, J.J., Puertas, E., García-Ovejero, E., Villalba, G., Condes, E., Koleva, G., Hurtado, C., Landecho, M. F. (2019), Comparison of machine learning algorithms for clinical event prediction (risk of coronary heart disease), Journal of Biomedical Informatics, 97, 103257. DOI: 10.1016/j.jbi.2019.103257

Chen M.C., Wu P.J. Hsu Y.H. (2019), An effective pricing model for the congestion alleviation of e-commerce logistics. Computers \& Industrial Engineering 129, 368-376. DOI: 10.1016/j.cie.2019.01.060

Djenouri, Y., Belhadi, A., Belkebir, R. (2018), Bees swarm optimization guided by data mining techniques for document information retrieval, Expert Systems with Applications, 94, 126-136. DOI: 10.1016/j.eswa.2017.10.042

Güven, H. (2020), Covid-19 sürecinde e-ticaret sitelerine yöneltilen müşteri şikâyetlerinin İncelenmesi. Electronic Turkish Studies, 15(4).

İnan, H. Doğan, H. (2006), Müşteri odaklı web sitelerinin işletme pazarlama kararlarına ve markasına etkisi. Çukurova Üniversitesi Sosyal Bilimler Enstitüsü Dergisi, 15(2), 191206.

Karayılmazlar, S., Bardak, T., Avcı, Ö., Kayahan, K., Karayılmazlar, A. S., Çabuk, Y., Kurt, R., İmren, E. (2019). Determining the orientation in choosing furniture based on social media based on data mining algorithms: Twitter example, Türkiye Ormancılık Dergisi, 2019(4), 447-457. DOI: 10.18182/tjf.609967

Khanbabaei, M., Sobhani, F. M., Alborzi, M., Radfar, R. (2018), Developing an integrated framework for using data mining techniques and ontology concepts for process improvement, Journal of Systems and Software, 137, 78-95. DOI: 10.1016/j.jss.2017.11.019

Laohapensang O. (2009). Factors influencing internet shopping behaviour: a survey of consumers in Thailand. Journal of Fashion Marketing and Management, 13 (4) 501513. DOI: $10.1108 / 13612020910991367$

Li, J., Lowe, D., Wayment, L., Huang, Q. (2020), Text mining datasets of $\beta$-hydroxybutyrate (BHB) supplement products' consumer online reviews, Data in Brief, 30, 105385. DOI: 10.1016/j.dib.2020.105385

MOSDER (Mobilya Sanayicileri Derneği) (2015), Mobilya Tüketici Araştırması 2015. http://www.mobilyadergisi.com.tr/haber/mosder-2015-mobilya-tuketicisi-arastirmasi Erişim Tarihi:17.02.2021.

Oliveira, C., Guimarães, T., Portela, F., Santos, M. (2019), Benchmarking Business Analytics Techniques in Big Data," Procedia Computer Science, 160, 690-695. DOI: 10.1016/j.procs.2019.11.026 
Patterson, P. G., Lester W. J., Richard A. S. (1997), Modeling the determinants of customer satisfaction for business-to-business professional services. Academy of Marketing Science, 25(1), 4-17. DOI: 10.1177/0092070397251002

Ribeiro, J., Duarte, J., Portela, F., Santos, M. F. (2019), Automatically detect diagnostic patterns based on clinical notes through Text Mining, Procedia Computer Science, 160, 684-689. DOI: 10.1016/j.procs.2019.11.027

Sarkis J., Meade L.M. Talluri S. (2004), E-logistics and the natural environment. Supply Chain Management: An International Journal 9 (4) 303-312. DOI: 10.1108/13598540410550055

Schedlbauer, J., Raptis, G., Ludwig, B. (2021), Medical informatics labor market analysis using web crawling, web scraping, and text mining, International Journal of Medical Informatics, 150, 104453. DOI: 10.1016/j.ijmedinf.2021.104453

Sözen, E., Bardak, T., Aydemir, D., Bardak, S. (2018), Yapay sinir ağları ve derin öğrenme algoritmaları kullanarak nanokompozitlerde deformasyonun tahmin edilmesi, Bartın Orman Fakültesi Dergisi, 20(2), 223-231. DOI: 10.24011/barofd.449563

Suki N.M., Ramayah T. Suki N.M. (2008), Internet shopping acceptance examining the influence of intrinsic versus extrinsic motivations. Direct Marketing: An International Journal, 2 (2) 97-110. DOI: 10.1108/17505930810881752

Türedi, H. (2010), Zonguldak ili mobilya sektöründe satış sonrası hizmet üzerine bir araştırma. Bartın Üniversitesi, Fen Bilimleri Enstitüsü, Orman Endüstri Mühendisliği Anabilim Dalı, Yüksek Lisans Tezi, 75 s.

URL-1.https://www.digitalplanet.com.tr/tr/blog/koronavirus-salgini-ile-gelisen-eticaret dunyasi-ve-edonusum-cozumleri-6956 (Erişim Tarihi: 01.02.2021)

Ülger, Y. T., Toksarı, M. (2020), E-Ticaret sitelerinin kullanılabilirliği ve başarısını etkileyen faktörlerin belirlenmesi, Giresun Üniversitesi İktisadi ve İdari Bilimler Dergisi, 6(2), 116-128. DOI: $10.46849 /$ guiibd.823445

Wen-Xiang, D., Jian-Ping, Z., Jing, L., Zhi-Ying, Y., Hua-Ying, W., Zhong- Hua, Y., Yi-Ge, Z., Wen-An, Z., Hui-Yong, H. (2019), Research on text mining of syndrome element syndrome differentiation by natural language processing, Digital Chinese Medicine, 2(2), 61-71. DOI: 10.1016/j.dcmed.2019.09.001

Yagci, I. A., Das, S. (2018), Measuring design-level information quality in online reviews, Electronic Commerce Research and Applications, 30, 102-110. DOI: 10.1016/j.elerap.2018.05.010

Yurtay, Y., Yavuzyılmaz, O., Bacınoğlu, N. Z., Ak, G. (2016), Mobilya Perakende Satış Sektöründe Veri Madenciliği Uygulaması, The Journal of Academic Social Sciences, 4(22), 385-385. DOI: 10.16992/ASOS.961

Zhang, C., Cao, L., Romagnoli, A. (2018), On the feature engineering of building energy data mining, Sustainable Cities and Society, 39, 508-518. DOI: 10.1016/j.scs.2018.02.016

Zhou, J., Cheng, C., Kang, L., Sun, R. (2018), Integration and analysis of agricultural market information based on web mining, IFAC-PapersOnLine, 51(17), 778-783, DOI: 10.1016/j.ifacol.2018.08.101 